\title{
Arte, belleza y amor: una ventana a lo trascendente*
}

\author{
Art, beauty and love: A Window to the transcendent \\ Recibido: 28 de septiembre de 2009 - Revisado: 18 de diciembre de 2009 - Aceptado: 28 de enero de 2009
}

Tamara Kobiec $^{* *}$

\section{Resumen}

En el presente trabajo se propone realizar una introducción al estudio del arte como una manera de encuentro con lo misterioso, lo inefable, basándose, por un lado, en los pensamientos de grandes artistas, filósofos y críticos de arte, tales como Tarkovski, Picasso, Unamuno y Steiner y, por otro, en los aportes realizados por la teología cristiana y la iconografía. Se realizará una lectura de la obra de arte en clave de esperanza: a través del silencio interior y la contemplación se puede encontrar la voz de aquella otra Belleza que atrae hacia Sí, mostrando cómo el Amor, la Belleza, la Bondad y la Verdad son diferentes caras de una misma realidad que supera la muerte, el dolor y la mentira.

\section{Palabras clave}

Belleza, amor, misterio, contemplación, arte, estética, Dios.

\begin{abstract}
In the present work we attempt to make an introduction to the study of art as a way of encounter with the mysterious and the ineffable. We will rely, on the one hand, on the thoughts of great artists, philosophers and critics of art, such as Tarkovsky, Picasso, Unamuno and Steiner, and, on the other hand, on the contributions made by Christian theology and Christian iconography. We will approach the work of art in the key of hope: through inner silence and contemplation we may find the voice of another Beauty which attracts us towards itself, showing us how Love, Beauty, Goodness and Truth are different sides of reality which transcends death, pain and lie.
\end{abstract}

Keywords

Beauty, love, mystery, contemplation, art, aesthetics, God.
* Artículo resultado de investigación.

** Tamara Kobiec es profesora en $\mathrm{Fi}$ losofía por la Pontificia Universidad Católica Argentina y licencianda de la misma universidad. Profesora asociada de Antropología en la Facultad de Ciencias Sociales de la Universidad Católica de La Plata, Argentina, y de Ética e Historia de la Filosofía Medieval en el Centro de Altos Estudios Cardenal John Henry Newman. Investigadora asociada del Grupo Lumen de la Escuela de Filosofía y Humanidad de la Universidad Sergio Arboleda de Bogotá, Colombia.

Correo electrónico:

tamara.kobiec@gmail.com 


\section{Introducción}

En el presente trabajo se propone realizar una introducción al estudio del arte como una manera de encuentro con lo misterioso, lo inefable, basándonos, por un lado, en los pensamientos de grandes artistas, filósofos y críticos de arte, tales como A. Tarkovski, P. Picasso y G. Steiner y, por otro, en los aportes realizados por la teología cristiana y la iconografía.

También se refiere brevemente a algunas posturas que se oponen a la concepción del arte estudiada, para así poder contraponerlas y criticarlas, viendo tanto sus puntos débiles como los fuertes, que pueden ayudar a completar el análisis.

Se utilizará una considerable cantidad de textos literarios, especialmente poesías, y reflexiones de artistas acerca de su quehacer puesto que se estima que es en estos donde la filosofía debe ir a buscar los elementos necesarios para poder realizar fructíferas investigaciones en esta área ya que le da luces y matices que difícilmente pueda alcanzar el puro pensamiento "racional", corriendo entonces el riesgo de quedarse en meras abstracciones o sin lograr ver aspectos esenciales de la cuestión.

Se decidió dividir en tres, siguiendo a J. Ratzinger (2002), las posturas acerca de la belleza y el arte que se trataran en este trabajo. Ahora se expondran brevemente y luego, a lo largo de todo el estudio, se iran haciendo referencia a las mismas.

En primer lugar, se encuentran la que denominaremos 'falsa belleza', que se cree es la que predomina actualmente en los medios de comunicación y la sociedad en general, la propuesta por la "industria cultural". Es esta la belleza que ciega, que encierra al hombre en sí mismo en vez de despertar sus ansias de absoluto, de entrega, de búsqueda. Provoca en el hombre la voluntad de poder, de posesión, de mero placer.
Es la belleza del fruto del árbol del Génesis, antes de la caída: Eva ve que el fruto es bello, bueno para comer y agradable a la vista. Esta experiencia, en vez de elevar a Eva, hace que se despierte en ella el deseo de posesión y se repliegue sobre sí misma. Es la belleza que se encuentra a diario, por ejemplo, en las publicidades o en ciertas películas; la belleza que, por no ser en realidad tal, deja al hombre vacío pues lo llena de nada.

Contra esta falsificación de la belleza han reaccionado las diferentes vanguardias. Estas cuestionan cuál es la verdadera belleza y también muchas veces quieren hacer un lugar a aquello o aquellos que quedan excluidos de la "industria cultural". Sin embargo a menudo esta crítica, que se piensa es muy legítima, suele aproximarse al extremo de realizar un cierto culto a lo feo y se cae en afirmar que, últimamente, el fondo de la realidad es la fealdad.

Nos encontramos entonces ante una lucha del artista contra la realidad, buscando directamente oponerse a ella, deformarla, deconstruirla: es el proceso que Ortega y Gasset (1942) llama la "deshumanización del arte", muy en boga ya hace un tiempo en diversos movimientos de vanguardia que tienen como base la filosofía nihilista. Estos artistas huyen de la realidad, la desprecian y tratan con sorna porque creen que no hay nada digno de respeto allí sino solo simulacros; no hay sustancias sino solo seres sin consistencia, sin esencia ni leyes, y la libertad del artista es por lo tanto absoluta.

Es esta, entonces, la segunda postura, la de quienes consideran que la mentira y la fealdad es la última palabra, no habiendo nada más allá de estas. Consideran que no tiene sentido seguir en la búsqueda porque la belleza y la verdad son solo máscaras que tapan el vacío de detrás y que tarde o temprano caerán.

Como afirma Jean Baudrillard:

Al igual que los barrocos, somos creadores desenfrenados de imágenes, pero en 
secreto somos iconoclastas. No aquellos que destruyen las imágenes sino aquellos que fabrican una profusión de imágenes donde no hay nada que ver. La mayoría de las imágenes contemporáneas, video, pintura, artes plásticas, audiovisual, imágenes de síntesis, son literalmente imágenes en las que no hay nada que ver; sin huella, sin sombra, sin consecuencias. Lo máximo que se presiente es que detrás de cada una de ellas ha desaparecido algo. Y solo son eso: la huella de algo que ha desaparecido (Baudrillard, 1991, p. 23).

Estas dos posturas tienen un núcleo en común: no hay "detrás" del arte nada que dé un fundamento a la belleza para que esta pueda ser tal. Frente a esto, las dos opciones: o bien tratar de tapar el "hueco" con algo que en realidad jamás podrá hacerlo, sino a lo sumo solo será una triste caricatura, o bien denunciar la falsedad de la caricatura y entonces "tragarse" nuestros deseos de absoluto y quedarse con la mentira, la fealdad, la oscuridad, en definitiva, el mal, como el último constitutivo de lo real.

Sin embargo, ¿por qué debemos suponer que no hay misterio ni trascendencia ni absoluto? ¿Se sigue acaso necesariamente de la presencia del dolor, el sufrimiento y la fealdad en el mundo que es esa la última palabra? Hay quienes han dicho que luego de Auschwitz ya no es posible volver a escribir poesía ni hablar de un Dios bueno, pero ¿es esto realmente así?

Se cree que existe la posibilidad de una tercera postura, que se abra a la presencia del misterio, de lo inefable, pero para ello son necesarias ciertas disposiciones tanto externas como, principalmente, internas, no solamente del artista sino también del receptor de la obra de arte. Dentro de ellas, se considera que son de principal importancia el silencio (exterior y también interior), la contemplación, la interioridad e interiorización, la reverencia, la donación de sí y la gratuidad, la cortesía y el amor.
Es en esta postura en la que profundizaremos en nuestro trabajo, ayudándonos con los conocimientos de la teología y la espiritualidad cristianas.

\section{Desarrollo}

\section{Belleza, nostalgia y esperanza}

Ya los autores antiguos, como Platón en el Fedro o el Banquete y Plotino en sus Enéadas, consideran el encuentro del hombre con la belleza como una experiencia que hace que este salga de sí mismo, que lo saca de la rutina y del acomodamiento de la vida cotidiana para recordarle que hay algo más allá de las "apariencias". La belleza es vista como productora de un éxtasis que, al "entusiasmarnos" y hacernos salir de nosotros mismos, nos abre también una herida ya que nos enfrentamos con nuestra ansia de absoluto y vemos que no hay nada que pueda saciarnos. Y esto sucede tanto ante la belleza natural como la de una obra creada por el hombre. De allí que afirme Charles Baudelaire:

Este admirable instinto de lo bello, nos hace considerar a la tierra y a sus espectáculos como un aspecto, como una "correspondencia" del cielo. (...) Y cuando un poema exquisito trae lágrimas a los ojos, esas lágrimas no son la prueba de un exceso de goce; son más bien el testimonio de una melancolía irritada (...), de una naturaleza desterrada en lo imperfecto y que quisiera apoderarse en esta tierra misma de un paraíso revelado (Baudelaire, citado en Mosto, 2002, p. 148).

Se cree que justamente el arte es posible porque existe en el hombre este anhelo de la Belleza y no puede alcanzarla: si no existiera este deseo ¿qué sentido tendría la existencia del arte? ¿Es posible imaginar un artista cuyo corazón no busque ardientemente esta Belleza? Y si ya la hemos alcanzado, ¿para qué el arte? En la condición humana, como diría George 
Steiner (2001), de ser que vive en el sábado, en el claroscuro, está la razón de ser del arte.

El hombre necesita de la belleza para sobrevivir, pero a la vez ve que la belleza que es posible contemplar aquí no le es suficiente, y esto hace decir nostálgicamente al poeta Francisco Luis Bernárdez en su Soneto lejano (1972, p. 89):

Bello sería el río de mi canto, que arrastra por el mundo su corriente, si dicho canto no naciera en cuanto el río se separa de la fuente.

Bello sería el silencioso llanto de la estrella en la noche de mi frente, si dicha estrella no distara tanto de quien le da la luz resplandeciente.

\section{Bello sería el árbol de mi vida si la raíz de amor lo sostuviera sin estar alejada y escondida.}

Bello sería el viento que me nombra si la voz que me llama no estuviera perdida en la distancia y en la sombra.

Se tiene solo una vaga percepción de lo que realmente anhelamos, de allí que se hable de ello como de un enigma. El objeto último de la nostalgia permanece sin nombre, aunque en el cristianismo se encuentra con un intento de respuesta:

Hombres que llevan en sí un deseo tan poderoso que supera su naturaleza, y que desean y anhelan más de aquello a lo que el hombre puede aspirar, estos hombres han sido traspasados por el mismo Esposo, él mismo ha enviado a sus ojos un rayo ardiente de su belleza. La profundidad de la herida revela ya cuál es el dardo, y la intensidad del deseo deja entrever Quién ha lanzado la flecha (Kabasilas, citado en Ratzinger, 2002).
Aquí se encuentra con una concepción de la belleza opuesta a un esteticismo superficial y al desprecio de la razón humana, con la belleza como una forma superior de conocimiento, que involucra al hombre todo y se haya en estrechísima relación con la verdad.

Es un camino para conocer a Dios mismo: a través de la belleza crece el deseo de conocerlo y crece también el amor a Él, al reconocerlo como fuente de la hermosura. De allí que afirme san Juan de la Cruz en su Cántico espiritual (1985, p. 28):

\section{$Y$ todos quantos vagan de Ti me van mil gracias refiriendo, y todos más me llagan, $y$ déxame muriendo un no sé qué que quedan balbuciendo.}

Cuando se deja conmover tanto por la belleza del mundo como por una obra de arte, es imposible que no se desee algo más allá de esto, pero para que esta experiencia ocurra se debe permitir que las cosas penetren en la interioridad.

Además la obra de arte no solo hace que se tenga nostalgia de la Belleza, la Bondad, la Verdad, el Absoluto, sino que se abra también a la esperanza de que algún día se alcance. Toda obra de arte es esencialmente escatológica: se remite a un mundo venidero en que los deseos serán satisfechos y donde se encuentra la propia identidad y autenticidad, un mundo que no puede darse aquí pero que contemplando la belleza se sabe que existirá:

Así, el arte adelanta un esbozo de algo que todavía no existe. No puede decir cómo será; pero da una garantía misteriosamente consoladora de que vendrá. Detrás de cada obra de arte se abre, no se sabe cómo. Algo surge. No se sabe qué es, ni dónde, pero se siente la promesa en lo más íntimo (Guardini, 1960b, p. 70). 


\section{Silencio, contemplación y misterio}

Santiago Kovadloff (1993) distingue entre dos clases de silencio: el de la epifanía y el de la oclusión. Este último es el silencio muerto, el del miedo o el hábito; no es en realidad un verdadero silencio sino que es más bien una palabra encubierta, posible pero omitida en esa ocasión. Es el silencio que no da frutos porque es ausencia de vida.

En cambio, el silencio de la epifanía es el fruto de la palabra plena, el hijo de su desarrollo último, su cenit. Ya no es palabra porque nos encontramos frente a lo inefable.

Es este silencio el que se exige tanto de parte del artista como del que observa la obra de arte, en el primero porque es necesaria la contemplación, la apertura a la riqueza de lo real, para luego tener qué transmitir. Debe tanto adentrarse en su propia alma, en su interioridad, como tener los ojos bien abiertos para conocer cuál es su tarea. Como afirma Picasso (1993, p. 63) hablando de su experiencia como pintor: "Un cuadro me viene de lejos; quién sabe de cuán lejos; yo lo he adivinado, lo he visto". El artista tiene que estar pronto a recibir su inspiración y esta solo se da a quien ha realizado la ascesis suficiente, el ayuno de los sentidos necesario para percibir la profundidad de lo real.

Es esencial al artista el sacrificio, la fidelidad a la vocación, el compromiso. Debe ser consciente del inmenso don que lleva en sus manos y entregarlo desinteresada y amorosamente a los demás.

De todas formas, también es necesario que de parte del espectador u oyente haya una entrega a la obra, para que esta pueda tomar nueva vida en su alma. Debe acallar sus muchos pensamientos y distracciones diarias para adquirir, en el silencio, una profunda capacidad de ver, de percibir incluso aquello que en realidad no puede ser visto pero cuya huella aparece en el campo de lo visible.
Se debe dejar conducir por un camino interior hacia la superación de nosotros mismos a través de la purificación de la mirada, que es en última instancia una purificación del corazón, para que pueda revelarse la belleza:

Lo bello queda oculto a los ojos de aquellos que no buscan la verdad. Precisamente el vacío interior de quien percibe el arte y lo juzga sin estar dispuesto a reflexionar sobre el sentido y la finalidad de la existencia de este, ese vacío seduce más de la cuenta y lleva a una fórmula vulgar y simplista, al "¡No gusta!" o " $¡$ No interesa!". Un argumento fuerte, pero es el argumento de quien ha nacido ciego e intenta describir un arco iris. Queda absolutamente sordo al padecimiento que sufre un artista para comunicar a los demás la verdad que experimenta en ello (Tarkovski, 2000, p. 65).

Es necesaria la cortesía, el tacto de corazón, la hospitalidad para que se produzca la verdadera experiencia estética.

Actualmente estamos rodeados por la 'falsa belleza' de la que se hablaba antes, que no responde ni lleva a la verdad, y que no nos exige que nos detengamos y silenciemos nuestra alma para ir a su encuentro, ya que en realidad no existe, sino que es una pura ficción que solo nos aleja más de nosotros mismos:

La moderna cultura de masas - una civilización de prótesis-, pensada para el "consumidor", mutila las almas, cierra al hombre cada vez más el camino hacia las cuestiones fundamentales de su existencia, hacia el tomar conciencia de su propia identidad como ser espiritual (Tarkovski, 2000, p. 66).

Pero ante esto, el artista debe redoblar su esfuerzo, aumentar su fe, ya que de no ser así muchos otros no podrán llegar hasta allí. Plotino en su primera Enéada considera que los que poseen la posibilidad de elevarse a la verdad deben ser o bien filósofos o artistas o 
amantes. Define a la tarea del artista como una contemplación creadora, a la que atribuye una suerte de carácter iniciático, que incluye una serie de ritos de purificación necesarios para que el alma pueda recibir la revelación que está llamada a transmitir, siendo esta una tarea sagrada. Al artista le está dado entrever aquello que los hombres comunes no logran percibir, pero solo de una manera oscura, y además luego le resulta imposible expresar cabalmente lo que ha visto, ya que es demasiado luminoso para él, y entonces lo ciega. Estamos ante el misterio. Y aquí, nuevamente, se puede hacer un paralelo con la mística cristiana, de la mano del Comentario a la 'Noche oscura' de San Juan de la Cruz (1985, p. 124):

Esta contemplación tenebrosa (...) le es al alma tan secreta para decir y ponerle nombre para decillo, que (...) no halla modo ni manera ni símil que le cuadre para poder significar inteligencia tan subida y sentimiento espiritual tan delicado (...), bien así como el que viese una cosa nunca vista cuyo semejante nunca jamás vio que, aunque la entendiese y gustase, no le sabría poner nombre ni decir lo que es.

Jeanne Hersch (1946) define la tarea de pintar como la de forjar "formas rotas", queriendo decir con esto que lo que se quiere apresar en un cuadro es infinito, imposible de abarcar por el hombre y entonces todo lo que podemos hacer es tratar de reproducir fragmentos, siempre incompletos e imperfectos, de lo absoluto, y el espectador de la obra advertirá en estas formas inacabadas la ausencia decisiva: la de su auténtico objeto del deseo:

Toda formalización es una puesta de límites que segmenta el absoluto. Pero a la vez, en ese segmento llamado forma, lo ausente -el absoluto en cuestión- se hace evidente al menos como falta. Es aquello que, como ausencia, se nota. (...). Escribe Jeanne Hersch en el año 1946: "En lo que el hombre experimenta o inventa hay siempre una parte de indefinido por donde se introduce el infinito. El infinito hincha como un fuerte viento la vela de todo esfuerzo humano. Pero en el arte se trata de encarnar, y toda encarnación es limitada. Será, pues, necesario que la renuncia al infinito en el proceso de la encarnación le confiera una especie de presencia en el seno de la obra limitada, que lo que ha sido sacrificado hable por su ausencia. El ascetismo de la forma se convierte así en un valor expresivo de lo que la forma no puede ni debe contener" (Kovadloff, 1993, pp. 140-141).

De la misma manera, podemos afirmar de la poesía que su función es la de poner palabra a lo que se sustrae de ella, logrando entonces el aumento de la inquietud en el corazón.

El arte no debe ser una anestesia ni un pasatiempo (como suelen serlo las bellezas falaces) sino una suerte de "tábano" que nos despierte y nos recuerde quiénes somos y a qué estamos llamados.

De lo que se trata es de hacer una obra de arte para que lo invisible pueda dejar su impronta en lo visible; lo indecible en lo decible.

\section{Belleza, arte y cristianismo}

Se considera que el cristianismo ha hecho grandes aportes a la cuestión tratada, de los cuales centraremos en dos: la iconografía y Jesucristo como la Belleza por antonomasia.

En cuanto a lo primero, nos parece interesante recordar la distinción que realiza Romano Guardini (1960a) dentro del arte sacro, entre imágenes de culto e imágenes de devoción.

La imagen de devoción es aquella en la que se continúan la reflexión de la fe, las búsquedas y luchas internas del artista, la indigencia de su existencia. Le hace evidente al hombre su propia interioridad y surge de la vida interior 
del individuo creyente, de la propia experiencia de la fe. Le hace sentir a quien la contempla que debe y puede seguir adelante, ayudándole en su camino. En la imagen de devoción desciende lo divino y el hombre a su vez se eleva, creando un ambiente de familiaridad.

En cambio, el sentido de la imagen de culto es que Dios se haga presente. Ante ella, tenemos una actitud de respeto, adoración, temor. El artista, más que crear algo, aquí sirve a Dios para que por su intermedio Él se manifieste. Es una imagen sagrada, en la que se percibe lo tremendum frente a la pequeñez de la criatura. Viene más bien de la trascendencia en vez de la interioridad. Su lugar propio es lo apartado y cerrado, donde se entra con sigilo y luego se vuelve a salir, siendo perceptible la "puerta" que se abre y se cierra.

Desde la imagen de culto habla el Espíritu, tal como rige en la Iglesia en cuanto totalidad, orientado a formar comunidad, a lograr forma del mundo; en la imagen de devoción rige el mismo Espíritu, pero en cuanto llama a la inmediatez de la relación entre el Yo humano y Dios, el "Dios y mi alma, y nada más", orientando los complejos caminos de la Providencia individual (Guardini, 1960a, p. 30).

El ícono se encuentra dentro del grupo de las imágenes de culto, es un sacramental ya que representa el misterio de Dios. Lo representa en cuanto camino que nos conduce a su encuentro. En el ícono la representación es presencia. Los íconos están creados para ofrecer acceso, a través de la puerta de lo visible, al misterio de lo invisible. Es un llamado que nos invita a la contemplación del misterio de Dios.

Es imposible que lo visible transmita la esencia del Dios inconcebible. Pero, así como las Sagradas Escrituras son una representación verbal, una imagen de la historia sagrada, también los íconos son una representación suya, pero no verbal, sino hecha con los toques del pincel y los colores, con las luces y un particular manejo del espacio.

En la iconografía aparece de una manera clara y también en cierto sentido superior, la presencia de lo inefable de la que hablábamos en el apartado anterior. Aquí se nota el carácter sacramental del arte, su "aura" de una forma más cercana, ya que es directamente una "ventana" al Absoluto. El hombre es un ser sacramental por naturaleza y necesita por tanto de los sacramentos y símbolos para establecer la comunión con lo inefable.

Como afirma G. Steiner, lo que ha hecho el arte en general es pedir "un préstamo de moneda vital, inversiones de fondo y créditos al banco o a la casa del tesoro de la teología. De allí hemos tomado prestadas nuestras teorías del símbolo, nuestro uso del icono, nuestra jerga del aura y la creación poética" (1997, p. 74).

La verdadera obra de arte es análoga a los íconos ya que abre a la presencia de lo otro y del Otro, y actúa como canal para su manifestación. En todas ellas lo invisible de alguna manera se deja experimentar por el que posee un corazón dispuesto a recibirlo:

Toda auténtica obra de arte desemboca en algo religioso. (...) No hago justicia a la obra de arte si la "disfruto", sino que tengo que compartir el encuentro del hombre creador con la cosa. Entro en el espacio que ahí se establece, y vivo en ese mundo más puro que surge. Al mirar, soy invadido por él. En sí mismo, se convoca "lo mejor", liberándose de la sujeción y opresión en que lo mantiene la existencia cotidiana. Pero precisamente ahí presiento lo que soy propiamente, y siento la promesa de que alguna vez podré alcanzarlo (Guardini, 1960b, p. 72).

Con respecto a la segunda cuestión a tratar, la belleza de Jesucristo, parece interesante recordar la reflexión que realiza san Agustín 
a partir del tercer versículo del salmo 45, 3 que reza: "Eres el más bello de los hombres/ en tus labios se derrama la gracia", y el texto del libro de Isaías $(53,2)$ que dice: "Sin figura, sin belleza. Lo vimos sin aspecto atrayente, con el rostro desfigurado por el dolor". Ambos textos son atribuidos en la Iglesia al Redentor y san Agustín (citado en Ratzinger, 2002) nota que hay aquí una paradoja, a la que se refiere con el nombre de las "dos trompetas". Según este autor, no hay aquí una contradicción sino que lo que hay son dos trompetas que suenan contrapuestas pero reciben el sonido del mismo aire, del mismo Espíritu divino.

Para Agustín aquí se produce una superación de la estética griega ya que lo bello en Jesucristo recibe una nueva profundidad, un realismo nuevo: el que es la Belleza ha permitido que lo escupieran, le desfigurar el rostro, lo coronaran de espinas, lo atravesaran con clavos y una lanza y finalmente lo crucificaran. En este rostro estropeado aparece la verdadera y suprema belleza: la belleza del amor, que llega hasta el extremo y se revela entonces más fuerte que la mentira y la violencia. Quien logre percibir esta belleza conocerá inmediatamente que la última palabra sobre la realidad es la verdad y no la mentira:

El que cree en Dios, en el Dios que precisamente en las apariencias alteradas de Cristo se manifestó como amor "hasta el final" $(\mathrm{Jn} 13,1)$, sabe que la belleza es verdad y que la verdad es belleza, pero en el Cristo sufriente comprende también que la belleza de la verdad incluye la ofensa, el dolor e incluso el oscuro misterio de la muerte, y que solo se puede encontrar la belleza aceptando el dolor y no ignorándolo (Ratzinger, 2002).

La revelación del hijo lleva a la plena luz lo que ya habían entrevisto los antiguos, especialmente Platón: hay una estrecha unión entre belleza y amor como también la hay entre estos y el dolor, pero es este un sufrimiento pleno de sentido pues se lo da el amor.
Esto también lo han visto los artistas, que saben que para crear belleza deben realizar una tarea dolorosa, siendo atormentados por los mismos temas y visiones, entregarse totalmente y escribir o pintar o componer una y otra vez acerca de lo mismo, como casi mártires que deben inclinarse ante la belleza:

Una idea realmente artística es siempre para el artista algo atormentador, algo casi peligroso para su vida (...) Un artista de verdad (...) sólo tiene derecho a una actividad creativa si para él es una necesidad vital (Tarkovski, 2000, p. 215).

Como dice G. Steiner (1994), en el arte hay un acto de amor por parte del artista que solo puede ser pagado con otro acto de amor por parte del receptor de la obra, a la que debe acoger hospitalariamente y con tacto del corazón. Se cree que en el amor se encuentra la esencia de la obra de arte, y no puede haber real belleza sin este, como tampoco puede haber amor sin belleza, pues el uno implica al otro. Afirma Pablo Picasso hablando de su tarea como artista: "En el fondo, no hay más que el amor. Sea el que sea. Y se debiera reventar los ojos a los pintores como se hace con los jilgueros para que canten mejor" (1973, p. 97).

Se piensa que Dios es el que le da el auténtico y último sentido a la obra de arte y a la belleza del mundo, y en Jesucristo, a través de su belleza y amor redentores, se puede conocer de manera intimísima esta realidad.

\section{Conclusión}

Se quiere terminar el trabajo con unos fragmentos de un poema de Miguel de Unamuno titulado Caña salvaje (1972, pp. 111-114), pues se considera que resume bellamente lo que se quiso expresar:

¿Es que soy algo más que frágil caña

por la que sopla el viento?

El viento del Señor, del infinito, 
sin arranque ni término.

Doblégate a su soplo

$y$ déjale que en ti susurre o brame,

siempre a su modo.

¿Arte? ¿Qué es eso de arte?

iNo te hagas caramillo,

sigue de caña!

Caña simple, salvaje,

que cela con sus hojas

las aguas del arroyo

que no reposa.

No, no junto al camino,

a distraer el viaje del peregrino,

no a alegrar las jornadas

del caminante,

sino aquí, en el retiro,

donde tan sólo llegan

de cuando en cuando

los que sin fin ni rumbo

vagan perdidos.

$Y$ tú, caña salvaje,

darás a tus oídos

la voz del viento del Señor eterno, del misterio los gritos.

Hoy de levante sopla,

mañana de poniente,

de norte o sur tal vez, o en remolino.

(...)

Lejos de los caminos

de artistas y viandantes,

por donde no trafican

buhoneros del arte,

donde los siervos del Señor se pierden

en la selva a que se entra

y no se sale,

la selva sin senderos,

como no sean

los que nos muestran el cielo,

los senderos de estrellas.

Caña, mi caña,

bajo el cielo estrellado

zumba de noche,

$y$ a los pobres durmientes

el sueño rompe.

Caña salvaje,

¿qué tienes, dime, tú que hacer con eso

que llaman arte?
Caña, mi caña,

doblégate al Señor, que a su albedrio

Él en ti cante;

en ti, caña salvaje,

sin plan alguno su poder ensaya;

juega contigo;

sé su juguete tú, mi pobre caña.

Creemos que en este poema se ve claramente cómo el arte, por un lado, es fruto de una suerte de "inspiración divina", ante la cual lo que el artista debe hacer es doblegarse y servirle y, por otro lado pero en estrecha relación con lo anterior, el arte nos lleva al encuentro con lo inefable: de Él viene y a Él nos lleva de regreso. El artista debe responder al llamado de Dios (justamente es eso lo que significa "vocación") para poder llevarlo a Él a los demás, que no poseen su don, pero sí tienen fe en el artista y andan, como dice Unamuno, perdidos, buscando la guía de la belleza y también la renovación de su esperanza.

El verdadero artista se escapa de los "buhoneros del arte", es decir, de los que quieren engañar con la falsa belleza, la que se busca por el mero goce del momento y no ayuda en el crecimiento del hombre sino que, al contrario, lo ensimisma y empobrece. Es esta la belleza "fácil", la que no cuesta ningún esfuerzo conseguir, pero que en realidad nos deja más vacíos que antes.

El artista no desea ser caramillo, sino caña: es decir, no quiere ser un instrumento rebuscado y mentiroso, sino un canal por el que pueda soplar el Espíritu lo más perfectamente posible, debiendo ser para esto liso, llano, dócil. Está llamado a romper el sueño de los durmientes, por lo tanto, a provocar heridas, guerra en sus corazones para que no se esfume en ellos la nostalgia de Dios, para que atrevan a internarse en los senderos de la selva en los cuales uno solo puede ser guiado por las estrellas.

No debe ser una distracción para el camino del peregrino, sino que, por el contrario, debe 
ayudar al retiro, al silencio y a la contemplación. Esta última debe ser también la tarea principal del artista, pues solo está "autorizado" a crear cuando se ha sido atormentado una y otra vez por las mismas inspiraciones, cuando ha madurado la creación en su interior, con un largo sufrimiento y también un inmenso amor y deseo profundo de procrear en la belleza.

El arte tiene como función dar "gritos del misterio", manifestar la presencia de lo Absoluto, dejándolo que "susurre o brame" a través suyo, tratando de ser un espejo de Aquello, y si cumple con esto, ya no habrá lugar para que se diga que el fondo de la realidad es feo o mentiroso, pues el dolor siempre presente estará traspasado por la luz, por el amor.

Se piensa que la respuesta a las dos posturas que se expusieron al comienzo del trabajo está aquí, pero no a la manera de una refutación racional pues se considera que no sería fructífero dar tal tipo de respuesta en una cuestión como la presente, en la que se debe apelar no solo al intelecto del hombre sino también y principalmente a su voluntad, a su corazón, y por ello se decidió realizarlo, mostrando que es posible otra salida si se anima a hacer silencio en el interior para escuchar la única voz que en definitiva puede llenarnos y que interpela a diario en la belleza y el amor de las personas, el mundo y las verdaderas obras de arte.

\section{Referencias}

Baudrillard, J. (1991). La transparencia del mal. Barcelona, Anagrama.

Bernárdez, F. L. (1972). Antología poética. Madrid, Austral.

De la Cruz, J. (1985). Poesías completas y comentarios en prosa. Madrid, Austral.

De Unamuno, M. (1972). Poesías escogidas. Buenos Aires, Losada.
Guardini, R. (1960a). Imagen de culto e imagen de devoción. Madrid, Guadarrama.

Guardini, R. (1960b). Sobre la esencia de la obra de arte. Madrid: Guadarrama.

Kovadloff, S. (1993). El silencio primordial. Buenos Aires, Emecé.

Mosto, M. (2002). 'La imagen y la mirada'. En Vida llena de sentido. Buenos Aires, Sabiduría cristiana.

Ortega y Gasset, J. (1942). La deshumanización del arte. Buenos Aires, Espasa-Calpe.

Picasso, P. (1973). Pintura y realidad. Montevideo, Libros del Astillero.

Plotino (1967). Enéadas. Buenos Aires, Aguilar.

Ratzinger, J. (2002). Mensaje a los participantes del "Meeting" de "Comunión y Liberación" de Rimini, del 24 al 30 de agosto. Disponible en: http://www.zenit.org/ article-15557?1=spanish

Sedlmayr, H. (1957). La revolución del arte moderno. Madrid, Rialp.

Steiner, G. (1994). En diálogo con Ramin Jahanbegloo. Madrid, Anaya.

Steiner, G. (1997). Pasión intacta. Bogotá, Norma.

Steiner, G. (2001). Presencias reales. Barcelona, Destino.

Tarkovski, A. (2000). Esculpir en el tiempo. Madrid, Rialp. 